\title{
Gambaran Sisa Makanan Pasien Rawat Inap RSUD Kabupaten Sidoarjo
}

\section{Inpatients Food Waste Description at Sidoarjo General Hospital}

\author{
Chusnul Fadilla ${ }^{1}$, Qonita Rachmah*1, Juwariyah²
}

\begin{abstract}
ABSTRAK
Latar Belakang: Kualitas mutu pelayanan gizi dapat dilihat melalui sisa makanan pasien hasil manajemen penyelenggaraan makanan rumah sakit. Tingginya sisa makanan dapat berdampak pada peningkatan risiko malnutrisi pada pasien rawat inap. Tujuan: Penelitian ini bertujuan untuk mengetahui gambaran sisa makanan pasien rawat inap di RSUD Kabupaten Sidoarjo.

Metode: Penelitian deskriptif ini menggunakan desain potong lintang dengan jumlah sampel sebanyak 150 pasien dipilih secara proportional sampling di masing-masing ruangan rawat inap pada bulan September 2019. Data diambil menggunakan formulir comstock lalu diterjemahkan dalam bentuk persen sisa makanan dan foodcost yang hilang. Tingginya persentase makanan ditentukan dengan standar Depkes 2013 yaitu apabila melebihi 20\%.

Hasil: Persentase sisa makanan pasien rawat inap tertinggi ditemukan pada lauk nabati $(30,72 \%)$ dan terendah pada lauk hewani $(21,81 \%)$. Semakin tinggi kelas rawat inap, maka semakin rendah persentase sisa makanan. Makanan yang utuh atau tidak tersentuh oleh pasien paling tinggi terjadi saat makan sore $(38,0 \%)$. Kerugian tertinggi akibat biaya yang hilang dari makanan utuh berasal dari rawat inap kelas I yaitu sebesar Rp. 1.680.000,00.

Kesimpulan: Sisa makanan pasien rawat inap di RSUD Kabupaten Sidoarjo masih tergolong cukup tinggi. Evaluasi faktor penyebab tingginya sisa makanan pada pasien rawat inap dapat dilakukan untuk menurunkan persen sisa makanan dan efisiensi foodcost.
\end{abstract}

Kata kunci: sisa makanan, pasien, rawat inap, rumah sakit

\section{ABSTRACT}

Background: The quality of nutrition services can be seen through the patient's leftovers as the result of hospital food system management. High food waste could impact on increasing the risk of malnutrition in hospitalized patients.

Objective: This study aimed to determine the food waste description among patients in Sidoarjo General Hospital.

Method: This was a descriptive study used a cross-sectional design with a total sample of 150 patients selected by proportional sampling in each in patient room during September 2019. Data was taken using the comstock form and then translated into percent of food waste and lost of food costs.

Results: The highest percentage of leftovers from hospitalized patients was found in vegetable side dishes (30.72\%) and the lowest was in animal side dishes (21.81\%). The higher class of inpatient room, the lower the percentage of food waste. Foods that were intact by patients were highest during dinner (38.0\%). The highest loss due to costs lost from whole food came from inpatient class I which amounted to IDR 1,680,000.

Conclusion: The food waste of inpatients at Sidoarjo General Hospital was still quite high. Evaluation of factors causing high food waste in inpatients can be done to reduce percent of food waste and food cost efficiency.

Keywords: food waste, patients, patient room, hospital

*Koresponden:

Qonita Rachmah

qonita.rachmah@fkm.unair.ac.id

${ }^{1}$ Departemen Gizi Kesehatan, Fakultas Kesehatan Masyarakat, Universitas Airlangga, Jl. Mulyorejo Kampus C, Surabaya, Jawa Timur, Indonesia, 60115.

2Instalasi Gizi, RSUD Kabupaten Sidoarjo, Jl. Mojopahit No.667, Sidoarjo, Jawa Timur, Indonesia, 61215. 


\section{PENDAHULUAN}

Pelayanan gizi di rumah sakit merupakan pelayanan yang diberikan kepada pasien dan disesuaikan dengan kondisi klinis, status gizi, maupun metabolisme tubuh. Salah satu pelayanan gizi di rumah sakit adalah adanya penyelenggaraan makan pasien. Penyelenggaraan makanan di rumah sakit merupakan rangkaian kegiatan dari perencanaan menu sampai dengan evaluasi yang bertujuan agar tersedianya makanan berkualitas sesuai kebutuhan gizi, biaya, aman, dan dapat diterima oleh konsumen untuk mencapai status gizi optimal ${ }^{1}$. Pelayanan makanan untuk pasien rawat inap merupakan salah satu pelayanan penunjang medik yang dapat membantu upaya perbaikan status gizi pasien, menurunkan risiko komplikasi, mortalitas, serta mengurangi durasi rawat inap sehingga menurunkan biaya pengobatan ${ }^{2}$. Melalui manajemen penyelenggaraan makanan di rumah sakit, salah satu kriteria keberhasilan kualitas penyelenggaraan makanan dapat dilihat dari sisa makanan pasien ${ }^{3}$. Sisa makanan pada pasien memberikan gambaran mengenai optimalisasi nilai gizi dari asupan makanan rumah sakit dan keberhasilan terapi diet. Adanya sisa makanan pasien juga berpengaruh terhadap biaya produksi yang terbuang.

Sisa makanan dapat diukur dengan penimbangan secara langsung maupun perkiraan jumlah menggunakan taksiran visual ${ }^{4}$. Metode comstock adalah salah satu metode taksiran visual yang menguntungkan karena mudah dilakukan, tidak mahal, dan tidak membutuhkan banyak waktu ${ }^{5}$. Oleh karena itu, metode ini seringkali digunakan untuk menilai sisa makanan di instansi yang menyelenggarakan makanan dengan jumlah banyak seperti rumah sakit.

Penelitian di salah satu rumah sakit Portugis menunjukkan bahwa sisa makanan masih menunjukkan presentase yang cukup besar yaitu 35\% dengan rincian setiap jenis makanan diantaranya $12 \%$ sup, $52 \%$ main course (pangan hewani), 54\% roti, dan $18 \%$ untuk buah ${ }^{6}$. Di Indonesia, sisa makanan dilihat dari 4 jenis makanan sesuai dengan kebiasaan makan yaitu nasi, lauk hewani, lauk nabati, dan sayur. Penelitian di Rumah Sakit Islam
Jemursari Surabaya menunjukkan bahwa rata-rata sisa makanan sekitar 25,1\%. Persentase sisa makanan tertinggi terdapat pada nasi $(31,73 \%)$ dan terendah pada lauk nabati $(16,6 \%)^{7}$. Angka rata-rata tersebut masih tergolong tinggi apabila dibandingkan dengan standar $\leq 20 \%{ }^{1}$.

RSUD Kabupaten Sidoarjo merupakan salah satu rumah sakit yang mengelola sendiri makanan pasien dalam jumlah besar. Setiap harinya, sekitar 600-700 pasien yang harus dipenuhi kebutuhan makannya. Pentingnya pembahasan mengenai sisa makanan pasien tidak hanya terkait pemenuhan gizi pasien, tetapi juga evaluasi penyelenggaraan makan di rumah sakit. Saat ini belum ada publikasi mengenai sisa makanan di RSUD Kabupaten Sidoarjo. Oleh karena itu, penulis ingin mengetahui gambaran sisa makanan di RSUD Sidoarjo terkait dengan mutu pelayanan gizi rumah sakit.

\section{METODE}

Penelitian dilaksanakan di RSUD Kabupaten Sidoarjo pada tanggal 9-11 September 2019. Pengambilan data dilakukan sebanyak 3 kali sehari yaitu setelah makan pagi (sekitar pukul 09.00), setelah makan siang (sekitar pukul 14.30), dan setelah makan malam (sekitar pukul 19.00). Penelitian sisa makanan dilakukan terhadap makanan pasien dengan bentuk nasi dan bubur kasar non diet pada ruang rawat inap kelas I, II, dan III RSUD Kabupaten Sidoarjo. Populasi berjumlah 237 plato (piring makan). Sampel dihitung menggunakan rumus proporsi populasi dengan $\mathrm{Cl} 95 \%, \alpha=0,05$ dan persentase sisa makanan penelitian rujukan yaitu $27,6 \%{ }^{8}$. Didapatkan hasil 135 sampel yang selanjutnya ditambah kemungkinan loss of follow up sebesar $10 \%$. Jadi, total sampel yang diambil sebanyak 150 sampel dan diambil secara merata pada seluruh ruang.

Pengumpulan data dilakukan dengan cara observasi dan pencatatan sisa makanan pasien yang telah dibawa kembali oleh pramusaji ke instalasi gizi dan sebelum dilakukan pembersihan menggunakan metode comstock. Jenis makanan yang diteliti terdiri dari nasi, lauk hewani, lauk nabati, dan sayur dengan ketentuan $0 \%$ 
(jika tidak ada sisa makanan/habis), 25\% (terdapat sisa makanan $1 / 4$ porsi), $50 \%$ (terdapat sisa makanan $1 / 2$ porsi), $75 \%$ (terdapat sisa makanan $3 / 4$ porsi), serta $100 \%$ (terdapat sisa makanan penuh/utuh). Selain itu, juga dianalisis jumlah porsi makanan yang utuh secara keseluruhan (tidak tersentuh pasien) karena alasan tertentu, misalnya pasien sedang operasi.

Pengambilan data dilakukan oleh 2-3 orang per ruangan dan per waktu makan dengan jobdesk diantaranya memilah plato berisi sampel sasaran (nasi dan bubur kasar non diet); membuka, mengamati, dan menentukan estimasi persentase sisa makanan per jenis makanan; serta melakukan pencatatan. Setelah data terkumpul, dilakukan pengolahan data terkait rata-rata persentase sisa makanan. Analisis persentase dapat dilihat dari komponen jenis makanan, ruangan terkait kelas rumah sakit, dan juga perbandingan siklus. Selain itu, sisa makanan utuh atau tidak tersentuh dikonversikan dalam bentuk rupiah yang hilang terkait dengan foodcost.

\section{HASIL DAN PEMBAHASAN}

Makanan rumah sakit memiliki berbagai variasi olahan, akan tetapi terdapat 4 jenis makanan utama yang dapat dilihat persentase sisa makanannya, meliputi nasi/makanan pokok, lauk hewani, lauk nabati, dan sayur (Gambar 1). Sisa makanan buah tidak di analisis karena tidak semua diet diberikan menu buah. Berdasarkan jenis makanannya didapatkan hasil bahwa lauk nabati paling banyak disisakan oleh pasien. Hal ini sejalan dengan keadaan di RSUD dr. Soeratno Gemolong yang menyebutkan bahwa jenis dan olahan lauk nabati pada rumah sakit terbatas sehingga berpengaruh terhadap penilaian pasien ${ }^{9}$. Jenis lauk nabati yang diberikan seringkali terbatas pada jenis tahu dan tempe dengan olahan yang juga terbatas, hal tersebut menyebabkan pasien malas menghabiskan dan sisa lauk nabati cukup tinggi pada pasien. Berbeda dengan penelitian oleh Habiba dan Adriani (2017) yang menyebutkan bahwa sisa lauk nabati paling sedikit karena keinginan konsumsi lauk lebih tinggi dibanding jenis makanan lainnya ${ }^{7}$. Persentase sisa sayur juga tidak jauh dari lauk nabati. Sisa sayuran yang tinggi dikarenakan rasa yang hambar, suhunya sudah dingin, dan warnanya tidak meningkatkan selera makan ${ }^{10}$. Sisa makanan paling sedikit adalah jenis lauk hewani yaitu $22 \%$. Angka terkecil pada jenis lauk hewani ini masih tergolong tinggi apabila dibandingkan dengan standar yang ada yaitu $\leq 20 \%$.

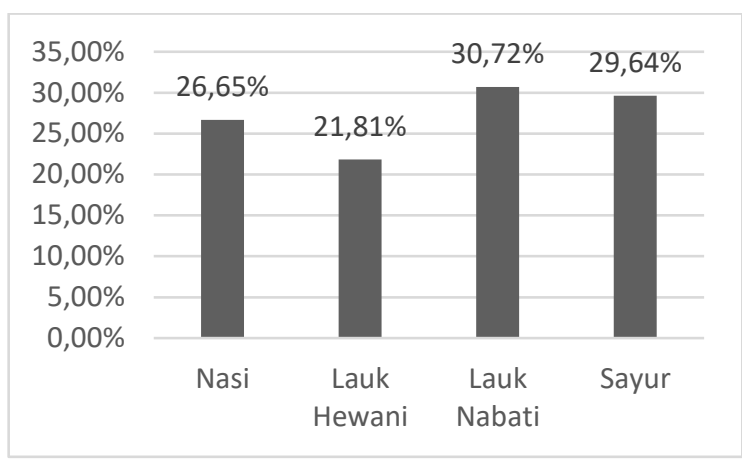

Gambar 1. Grafik persentase sisa makanan berdasarkan jenis makanan

Adanya sisa makanan di setiap ruangan dapat menunjukkan karakteristik kesukaan pasien terhadap makanan yang telah disediakan rumah sakit. Analisis sisa makanan di RSUD Sidoarjo berdasarkan ruangan dibedakan menjadi 5 ruangan (Gambar 2). Sisa makanan tertinggi terdapat pada ruangan mawar kuning dan mawar merah putih. Kedua ruangan tersebut merupakan ruangan untuk pasien kelas III. Angka persentase menurun seiring dengan adanya peningkatan kelas. Hal tersebut dibuktikan dengan ruangan Tulip (Rawat Inap kelas I) yang memiliki persentase terendah diantara ketiga kelas rawat inap. Meskipun begitu, ruang VK merupakan ruangan yang paling sedikit menyumbang sisa makanan di Instalasi Gizi RSUD Sidoarjo. Semakin tinggi ruang kelas rawat inap, maka semakin lengkap fasilitas yang diberikan. Pasien dengan kelas yang lebih tinggi, lebih puas terhadap pelayanan rumah sakit ${ }^{11,12}$. Hasil penelitian yang sama ditemukan di RSUP Sanglah, Bali dimana sisa makanan pasien paling banyak ditemukan di kelas 2 dan 3 yaitu sebanyak 85,3\%. Citarasa dan penampilan merupakan hal yang berkaitan dengan persepsi pasien terhadap makanan rumah sakit ${ }^{17}$. Semakin baik citarasa, maka semakin sedikit pula sisa makanan pasien ${ }^{19}$. Hal tersebut juga berlaku pada penampilan. Penyajian makanan di RSUD Sidoarjo untuk kelas I, II, maupun III menggunakan plato stainless. 
Perbedaannya ada pada bentuk plato dan penyajian sayur. Ruang perawatan kelas I menggunakan plato stainless bulat dan penyajian sayur dimasukkan terlebih dahulu ke dalam plastik, sedangkan kelas II dan III menggunakan plato stainless persegi panjang dengan penyajian sayur langsung diletakkan pada plato. Perbedaan penyajian makanan dapat mempengaruhi persepsi pasien dan mempengaruhi konsumsi makanan yang berasal dari rumah sakit ${ }^{17}$.

\begin{tabular}{|c|c|c|c|c|c|}
\hline $40,00 \%$ & $33,65 \%$ & & & & \\
\hline $30,00 \%$ & & $28,88 \%$ & $26,93 \%$ & $24,43 \%$ & 20 $14 \%$ \\
\hline $20,00 \%$ & & & & & \\
\hline $10,00 \%$ & & & & & \\
\hline \multirow[t]{2}{*}{$0,00 \%$} & & & & & \\
\hline & Mawar merah putih & Mawar kuning & Teratai & Tulip & VK \\
\hline
\end{tabular}

Gambar 2. Grafik Persentase Sisa Makanan berdasarkan Ruang Rawat Inap

RSUD Sidoarjo memiliki tipe siklus menu $10+1$ yang digunakan bergantian setiap harinya. Pengamatan sisa makanan dengan metode comstock dilakukan ketika Instalasi Gizi menggunakan siklus ke 9, 10, dan 1 (Gambar 3). Menu dalam siklus disajikan dalam tabel 1. Sisa makanan paling sedikit terlihat pada siklus ke-10, sedangkan siklus ke-9 dan ke-1 memiliki angka persentase yang hampir mendekati sama. Menu ke-9 dan ke-1 memiliki kesamaan yaitu penggunaan bandeng sebagai lauk hewani. Ikan bandeng memiliki duri yang banyak dan tersebar di seluruh bagian daging ${ }^{13}$. Hal tersebut dapat mempengaruhi kesukaan makan dan meningkatkan kemungkinan pasien tidak mau menghabiskan makanannya. Siklus menu digunakan untuk menjaga variasi menu. Semakin banyak variasi menu yang ada, semakin tinggi kepuasan pasien ${ }^{14}$.

Tabel 1. Siklus menu ke 9, 10, dan 1

\begin{tabular}{|c|c|c|}
\hline Siklus 9 & Siklus 10 & Siklus 1 \\
\hline Pagi & Pagi & Pagi \\
\hline -Nasi/BK & -Nasi/BK & -Nasi/BK \\
\hline \multirow[t]{3}{*}{-Kare daging + tahu berkuah } & \multirow[t]{3}{*}{-Opor ayam + tempe berkuah } & -Empal daging \\
\hline & & -Tempe bacem \\
\hline & & -Rawon manisah \\
\hline Siang & Siang & Siang \\
\hline -Nasi/BK & -Nasi/BK & -Nasi/BK \\
\hline -Asem-asem bandeng & -Telur dadar & -Bandeng goreng/bali \\
\hline -Tempe mendoan & -Tahu goreng/oseng & -Tahu orem \\
\hline -Sayur asem kray kangkung & -Cah tauge panjang & -Urapan kenikir toge/Cah kangkung toge \\
\hline Sore & Sore & Sore \\
\hline -Nasi/BK & -Nasi/BK & -Nasi/BK \\
\hline -Bistik ayam suwir & -Patin goreng & -Ceplok telur \\
\hline -Oseng tahu & -Tempe bumbu bali & -Tempe asem manis \\
\hline -Sup gambas & -Capcay sayur & -Lodeh terong \\
\hline
\end{tabular}
Ket: BK = Bubur kasar

Penelitian ini juga menemukan adanya food waste $100 \%$ atau tidak dikonsumsi sama sekali. Berdasarkan perhitungan sisa makanan selama 3 hari didapatkan data porsi makanan utuh yang sama sekali tidak disentuh oleh pasien pada setiap ruangan rawat inap. Penyebabnya bermacam-macam, dapat disebabkan oleh pasien yang sedang operasi, puasa, atau memang tidak mau dengan makanan rumah sakit. Data akumulasi 
jumlah makanan utuh selama 3 hari dapat dilihat pada tabel 2 dan gambar 4. Pemberian makanan pada pasien yang akan operasi atau puasa masih sering terjadi karena jadwal operasi yang mendadak atau kurangnya komunikasi antara perawat rawap inap dan bagian penyelenggaraan makanan. Oleh karena itu, penelitian ini menyarankan agar dibentuk SOP khusus untuk mengatur penjadwalan makan pasien, terutama untuk yang akan operasi atau dijadwalkan puasa untuk tidak diberi makanan terlebih dahulu guna menghindari food waste $100 \%$. Selain itu, konseling oleh ahli gizi juga diperlukan untuk beberapa pasien yang menurun nafsu makannya agar tingkat waste makanan tidak terlalu tinggi.

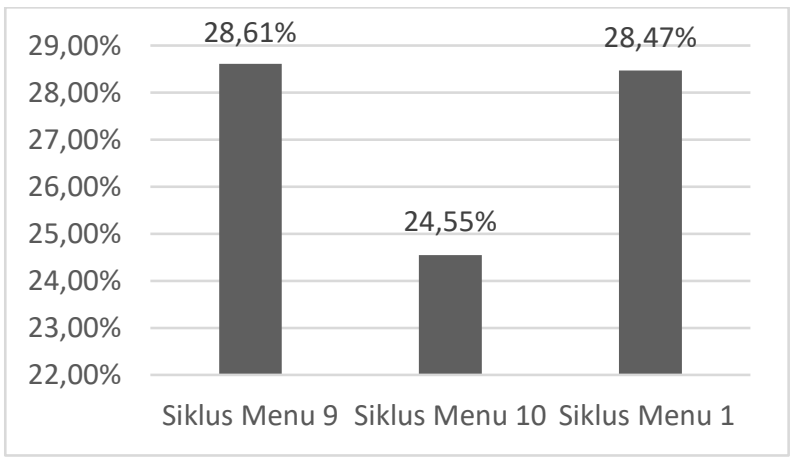

Gambar 3. Grafik Persentase Sisa Makanan berdasarkan Siklus Menu

Jumlah makanan yang utuh selama 3 hari pengamatan adalah 155 porsi dengan persentase dalam waktu makan pagi, siang, dan sore berturut-turut adalah 29\%, 33\%, dan 38\%. Makan sore/malam memiliki nilai tertinggi dan berbanding terbalik dengan penelitian oleh Fadilah (2013) yang menyebutkan bahwa sisa makanan tertinggi saat makan pagi ${ }^{15}$. Beberapa hal yang dapat menyebabkan tingginya sisa makanan di waktu makan tertentu adalah variasi menu yang terbatas, penampilan makanan dan perpaduan rasa makanan ${ }^{18}$. Hasil observasi menunjukkan variasi menu makan sore di siklus hari ke-9 dan 10 hampir sama yaitu kare daging dan tahu berkuah pada hari ke-9 dan opor ayam dan tahu berkuah pada hari ke-10. Hal ini dapat menjadi pertimbangan bagi tim penyelenggaran makanan RSUD Sidoarjo saat merencanakan siklus menu selanjutnya. Makanan yang utuh atau tidak tersentuh sama sekali oleh pasien dapat menimbulkan kerugian bagi Instalasi Gizi. Hal ini berkaitan dengan biaya makanan yang hilang. Setiap kelas memiliki anggaran tersendiri mengenai pembiayaan makanan rawat inap.

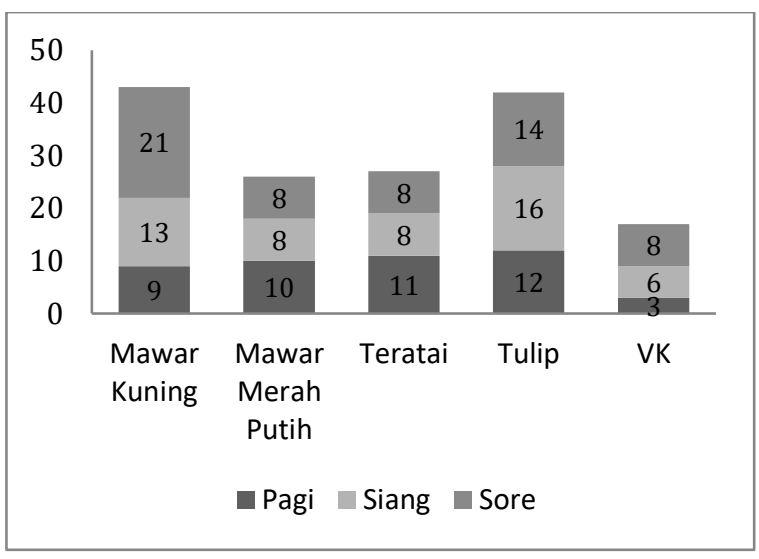

Gambar 4. Makanan Tidak Tersentuh Pasienberdasarkan Waktu Makan

Biaya makan untuk rawat inap kelas III sebesar Rp35.000,- sedangkan untuk kelas I dan II sebesar Rp40.000,-. Biaya makanan untuk ruang rawat inap VK sama seperti kelas III. Apabila jumlah makanan utuh dikonversikan sesuai harga makanan, maka dapat dilihat kerugian yang dialami oleh Instalasi Gizi terkait pembiayaan makanan untuk rawat inap (Gambar 5). Kerugian tertinggi dialami oleh ruang Tulip dan terendah dialami oleh ruangan VK. Rata-rata kerugian ruang mawar merah putih, mawar kuning, teratai, tulip, dan VK secara berurutan tiap harinya adalah Rp303.333, Rp501.667, Rp360.000, Rp560.000, dan Rp198.333.

Tabel 2. Jumlah Makanan Tidak Tersentuh Pasien

\begin{tabular}{lc}
\hline \multicolumn{1}{c}{ Ruangan } & Jumlah \\
\hline Mawar merah putih & 26 \\
\hline Mawar kuning & 43 \\
\hline Teratai & 27 \\
\hline Tulip & 42 \\
\hline VK & 17 \\
\hline
\end{tabular}

Tingginya kerugian di ruang tulip selain disebabkan oleh tingginya biaya makan juga disebabkan oleh banyaknya jumlah makanan utuh. Tulip merupakan ruang rawat inap kelas I sehingga kemungkinan pasien tidak menyukai makanan rumah sakit dan memilih membeli makanan di luar sehingga sisa makanan yang 
dihasilkan tinggi. Hasil ini sejalan dengan penelitian di RSU Haji Jakarta yang juga mendapati sisa makanan banyak di kelas perawatan $\mathrm{I}^{20}$. Tingginya kepuasan pasien tidak selalu berpengaruh terhadap tingkat konsumsi. Adanya konsumsi makanan dari luar dimungkinkan juga berpengaruh terhadap tingkat konsumsi pasien terhadap makanan rumah sakit ${ }^{16}$. Oleh karena itu, diperlukan peningkatan kualitas pelayanan makanan rumah sakit disertai dengan edukasi mengenai pentingnya menghabiskan makanan yang telah disajikan. Selain itu, makanan utuh dapat disebabkan oleh nama pasien yang masih tercantum dalam billing permintaan makan sedangkan pasien telah pulang. Hal ini karena belum dilakukan kunjungan oleh ahli gizi pada pagi hari dan adanya pasien yang masih menjalani operasi sampai siang hari.

\begin{tabular}{|c|c|c|c|c|c|}
\hline$R p 2.000 .000$ & & Rn1 505.000 & & 1.680 .0 & \\
\hline Rp1.000.000 & Rp910.000 & & Rp1.080.000 & & Rp595.000 \\
\hline \multirow{2}{*}{ Rp0 } & & & & & \\
\hline & Mawar Merah Putih & Mawar Kuning & Teratai & Tulip & VK \\
\hline
\end{tabular}

Gambar 5. Jumlah Kerugian akibat Makanan Tidak Tersentuh Pasien selama 3 Hari

Beberapa hal yang menjadi kelebihan pada penelitian ini adalah kajian sisa makanan di RSUD Sidoarjo yang sebelumnya belum pernah di publikasikan dan disertai dengan perhitungan beban kerugian dana. Adanya analisis yang mendalam dapat menjadi masukan yang berharga bagi pihak manajemen rumah sakit. Selain itu, sampel yang diambil juga cukup besar sehingga hasilnya lebih representatif. Namun, belum dibahas lebih lanjut terkait factor-faktor yang mungkin berpengaruh pada tingginya sisa makanna.

\section{KESIMPULAN}

Data hasil survei sisa makanan di Instalasi Gizi RSUD Sidoarjo berdasarkan jenis makanan, ruangan, maupun siklus menu menunjukkan tingginya angka sisa makanan pasien karena melebihi $20 \%$ sebagai standar. Beberapa hal yang dapat menjadi penyebab tingginya sisa makanan di RSUD Sidoarjo diantaranya jenis makanan yang terbatas khususnya lauk nabati, perbedaan penyajian pada setiap kelas rawat inap, kurangnya variasi dan jenis bahan makanan yang dipilih pada setiap siklus menu, maupun pasien tidak menyentuh makanan sama sekali karena sedang operasi atau pulang. Jumlah makanan yang tidak tersentuh pasien pun merepresentasikan kerugian yang cukup tinggi. Oleh karena itu, perlu dilakukan perbaikan kualitas pelayanan penyelenggaraan makanan. Salah satu hal yang dapat dilakukan adalah dengan melakukan survei kepuasan pasien secara berkala dan memperhatikan preferensi pasien terhadap makanan sehingga pasien merasa nyaman dengan makanan yang telah disediakan. Selain memperhatikan preferensi pasien, makanan yang disajikan juga harus tetap mengacu pada diet yang seharusnya sesuai penyakit yang diderita. Pada penelitian selanjutnya perlu digali lebih dalam mengenai faktorfaktor yang menyebabkan tingginya sisa makanan pasien di RSUD Kabupaten Sidoarjo yaitu faktor internal seperti usia pasien, jenis kelamin, status kesehatan, diagnosis medis, kebiasaan makan), faktor eksternal seperti suhu makanan, aspek organoleptik makanan,, porsi dan variasi bahan makanan), dan faktor lingkungan (makanan luar rumah sakit).

\section{ACKNOWLEDGEMENT}

Kami ucapkan terima kasih kepada pihak diklit dan ahli gizi RSUD Sidoarjo dalam membantu terselesaikannya penelitian ini.

\section{REFERENS}

1. Departemen Kesehatan RI. Pedoman Pelayanan Gizi Rumah Sakit. (Kementerian Kesehatan RI, 2013).

2. Aliffianti, R. Tingkat Kepuasan Pasien pada Pelayanan Makanan di Rumah Sakit 'Aisyiyah Purworejo. (Universitas Negeri Yogyakarta, 2015).

3. Kementerian Kesehatan Republik Indonesia. Keputusan Menteri Kesehatan Republik Indonesia 
Nomor: 129/Menkes/SK/II/2008 Tentang Standar Pelayanan Minimal Rumah Sakit (2008).

4. Williams, P. \& Walton, K. Plate waste in hospitals and strategies for change. e-SPEN, the European eJournal of Clinical Nutrition and Metabolism 6(6), e235-e241 (2011).

5. Susyani, Prawirohartono, E. P. \& Sudargo, T. Akurasi Petugas dalam Penentuan Sisa Makanan Pasien Rawat Inap Menggunakan Metode Taksiran Visual Skala Comstock 6 Poin. Jurnal Gizi Klinik Indonesia 2(1): 37-42 (2005).

6. Dias-Ferreira, C., Santos, T. \&Oliveira, V. Hospital food waste and environmental and economic indicators - A Portuguese case study. Waste Management 46, 146-154 (2015).

7. Habiba, R. A. \& Adriani M. Hubungan Depresi, Asupan, dan Penampilan Makanan dengan Sisa Makan Pagi Pasien Rawat Inap (Studi di Rumah Sakit Islam Jemursari Surabaya). Amerta Nutr, 198-208 (2017). DOI : 10.2473/amnt.v1i3.2017.198-208.

8. Fatkhurohman, Lestari, Y.N. \& Torina, T.D. Hubungan Perubahan Standar Porsi Makan dengan Sisa Makanan Pasien Rumah Sakit Holistik Tahun 2016. Jurnal Gizi Indonesia 40(1), 1-8 (2017).

9. Ariyanti, V. Hubungan antara Karakteristik Sensorik Makanan dengan Sisa Makanan Biasa pada Pasien Rawat Inap RSUD Dr. Soeratno, Gemolong, Kabupaten Sragen. (Universitas Muhammadiyah Surakarta, 2016).

10. Tanuwijaya, L. K., Sembiring, L. G., Dini, C. Y., Arfiani, E. P. \& Wani, Y. A. Sisa Makanan Pasien Rawat Inap: Analisis Kualitatif. Indonesian Journal of Human Nutrition 5(1), 51-61 (2018).

11. Erilisanawati, E. Perbedaan Tingkat Kepuasan Pasien Rawat Inap Berdasarkan Kelas Perawatan di RSUD Dr. Soediran Mangun Sumarso Kabupaten Wonogiri. (Universitas Muhammadiyah Surakarta, 2018).
12. Ripha, R. W. Pengaruh Kualitas Pelayanan Kesehatan, Kelas Perawatan dan Klasifikasi Pasien terhadap Kepuasan Pasien Rawat Inap di Rumah Sakit Umum Daerah Dr. Murjani Sampit. (Universitas Muhammadiyah Surakarta, 2018).

13. Dewi, E. N., Purnamayati, L. \& Kurniasih R. A. Karakteristik Mutu Ikan Bandeng (Chanos chanos Forsk.) dengan Berbagai Pengolahan. Jurnal Pengolahan Hasil Perikanan Indonesia 22(1),41-49 (2019).

14. Tanuwijaya, L. K., Novitasari, T. D., Arfiani, E.P., Wani, Y. A. \& Wulandari D. E. Kepuasan Pasien Terhadap Variasi Bahan Makanan di Rumah Sakit. Jurnal Gizi 8(1), 50-58 (2019).

15. Fadilah, O. Gambaran Sisa Makanan, Kontribusi Zat Gizi Dan Biaya Makan Pasien Rawat Inap Di RSUD Salatiga. (Universitas Muhammadiyah Surakarta, 2013).

16. Yulianti, I. Sisa Makanan dan Kepuasan pada Pasien Rawat Inap Kelas III di Rumah Sakit Swasta di Gresik, Jawa Timur. (Institut Pertanian Bogor, 2013).

17. Wirasamadi NL, Adhi KT, Weta IW. Analisis sisa makanan pasien rawat inap di RSUP Sanglah Denpasar Provinsi Bali. Public Health and Preventive Medicine Archive,3(1), 88-95 (2015).

18. Anwar I, Herianandita E, Ruslita I. Evaluasi sistem penyelenggaraan makanan lunak dan analisis sisa makanan lunak di beberapa rumah sakit di DKI Jakarta, tahun 2011. GIZI INDONESIA, 35(2) (2012).

19. Lironika A, Suryadi MY. Jadwal Distribusi dan Citarasa Makanan Berhubungan dengan Sisa Makanan Pasien di Ruang Perawatan Obgyn dan Bedah RSD. dr. Soebandi Jember. Amerta Nutr, 194200 (2019). doi: 10.20473/amnt.v3.i3.2019.194200

20. AULA, Lisa Ellizabet, et al. Faktor-faktor yang berhubungan dengan terjadinya sisa makanan pada pasien rawat inap di Rumah Sakit Haji Jakarta. (Universitas Islam Negeri, Jakarta, 2011). 